\title{
Análise da rede de apoio e do apoio social na percepção de usuários e profissionais da proteção social básica
}

Adolfo Pizzinato. Universidade Federal do Rio Grande do Sul. Esequiel Pagnussat. Universidade Federal do Rio Grande do Norte.

Ezequiel Simonetti Cargnelutti. Pontifícia Universidade Católica do Rio Grande do Sul. Nathália dos Santos Lobo. Pontifícia Universidade Católica do Rio Grande do Sul. Roberta Fin Motta. Pontifícia Universidade Católica do Rio Grande do Sul.

\section{Resumo}

Este artigo analisa articulações da Rede de Apoio e de diferentes funções do Apoio Social de usuários da Proteção Social Básica, através da percepção de trabalhadores do CRAS e de seus usuários, em Porto Alegre (RS). As entrevistas foram analisadas através da Análise Temática e os resultados codificados, contrastando as percepções de profissionais e de usuários. Os resultados indicam um enfraquecimento precoce de vínculos familiares e um reordenamento da Rede de Apoio, através de novos vínculos com a família extensa e a comunidade, como estratégia de enfrentamento, na história de vida dos usuários. Em relação aos sistemas informais, as instituições religiosas são relacionadas com o apoio material, enquanto que nos sistemas formais os profissionais da assistência social desempenham uma importante fonte de apoio emocional, destacando-se nas narrativas tanto de usuários como dos profissionais.

Palavras-chave: apoio social; rede de apoio; proteção social básica; assistência social.

\section{Abstract}

Analysis of the support network and the social support in perception of users and professionals of the basic social protection. This article analyzes the articulations of the Support Network and the different functions of Social Support for Basic Social Protection users, through the perception of CRAS workers and their users, in Porto Alegre (RS). The interviews were analyzed using Thematic Analysis and the results were codified, contrasting the professionals' and the users' perceptions. The results indicate an early weakening of family ties and a reordering of the Support Network through new links with the extended family and the community, as a strategy of coping, in users' life history. Regarding the informal system, the religious institutions are related to the material support, while in the formal systems, the professionals of Social Assistance play an important source of emotional support, inserting themselves in the Support Network, highlighting the narratives, both for users and for professionals. Keywords: social support; support network; basic social protection; social assistance.

\section{Resumen}

Análisis de la red de apoyo y del apoyo social en la percepción de usuarios y profesionales de la protección social básica. Este artículo analiza articulaciones de la Red de Apoyo y de distintas funciones del Apoyo Social de usuarios de la Protección Social Básica, a través de la percepción de trabajadores de los CRAS y de sus usuarios, en Porto Alegre (RS). Las entrevistas se analizaron mediante análisis temático y los resultados codificados, contrastando las percepciones de los profesionales y usuarios. Los resultados indican un debilitamiento precoz de los lazos familiares y un reordenamiento de la Red de Apoyo, a través de nuevos vínculos con la familia extensa y la comunidad, como estrategia de afrontamiento en las historias de vida de los usuarios. En cuanto a los sistemas informales, las instituciones religiosas son relacionadas con el soporte material, mientras que en los sistemas formales, los profesionales de la Asistencia Social desempeñan una importante fuente de apoyo emocional, destacándose tanto en las narrativas de los usuarios como en las de los profesionales.

Palabras clave: apoyo social; red de apoyo; protección social básica; asistencia social. 
A Assistência Social foi estabelecida como política pública a partir da promulgação da Constituição Federal do Brasil de 1988 e da Lei Orgânica da Assistência Social (LOAS) de 1993, compondo a Seguridade Social, juntamente com a Saúde Pública e a Previdência Social, cujo objetivo é garantir autonomia e condições dignas de vida à população brasileira (Ministério do Desenvolvimento Social e Combate à Fome [MDS], 2006). Em 2004 foi formulada a Política Nacional de Assistência Social (PNAS), visando à construção e a regulação do Sistema Único de Assistência Social (SUAS). A PNAS objetiva a proteção da família e a ruptura com a hegemonia de ações de caráter assistencialista, clientelista e de caridade, historicamente vinculadas à Assistência Social no Brasil (Oliveira \& Amorim, 2012). A família, nessa política, é entendida não somente por vínculos consanguíneos entre seus membros, mas também por laços afetivos ou de solidariedade. Essa noção ampliada pretende dar conta das transformações societárias contemporâneas, extrapolando as três dimensões clássicas de definição de família: sexualidade, procriação e convivência (MDS, 2004).

Assim, com o intuito de cumprir os objetivos e seguindo os princípios e diretrizes da LOAS e da PNAS, - SUAS propõe sua intervenção a partir de duas grandes estruturas articuladas entre si: a Proteção Social Básica (PSB), que atua na prevenção de situações de risco social, e a Proteção Social Especial (PSE), que atua em situações de média e alta complexidade de risco social (MDS, 2004). A unidade em torno da qual se organizam os serviços de PSB é o Centro de Referência de Assistência Social (CRAS), sendo sua obrigação ofertar o Serviço de Proteção e Atendimento Integral à Família (PAIF). As ações que compõem o trabalho social com famílias do PAIF se organizam em caráter individual ou coletivo, através de acolhimentos, oficinas com famílias, ações comunitárias, encaminhamentos e ações particularizadas (MDS, 2012).

Conforme preconizado pelo SUAS (MDS, 2012), as ações socioassistenciais realizadas pelos trabalhadores do PAIF visam efetivar os seguintes objetivos: fortalecer a função protetiva da família e prevenir a ruptura de vínculos familiares e comunitários; promover aquisições materiais e sociais, potencializando o protagonismo e a autonomia das famílias e da comunidade; promover acesso à rede intersetorial, à rede de proteção da assistência social e dos benefícios, e a programas e serviços socioassistenciais e apoiar famílias compostas por pessoas que necessitem de atenção social especial. Em diferentes contextos, a família mostra-se como a principal fonte de Apoio Social (Hermel et al., 2016; Lietz, Lacasse, \& Cacciatore,
2011), o que justifica a importância da intervenção em nível familiar. Além disso, a intervenção na rede - familiar e comunitária - amplia as possibilidades de atuação e de tratamento, evitando o "encapsulamento do campo de intervenção" na figura de alguma pessoa da família ou comunidade, em uma perspectiva mais psicossocial (Dabas, 1995; Klefbek, 2000; More, 2005).

Para que estratégias psicossociais de apoio sejam melhor discutidas no campo da Psicologia, é preciso que conceitos como rede social, rede de apoio, vínculos e Apoio Social figurem não apenas no léxico dos profissionais da área, mas como dispositivos chave de ação crítica. Neste sentido, a rede social pode ser entendida como conjunto de relações significativas de cada pessoa, ou seja, a "soma de todas as pessoas que o indivíduo percebe ou sente como significativas ou diferentes do universo relacional no qual está inserido", independentemente do campo de ação que se analise (Sluzki, 1997, p. 42). Tanto para Sluzki (1997) como para Gracia (1997), a rede social possui um importante papel para o reconhecimento potencial da agência de cada pessoa e para a construção de sua noção de si, bem como pressupõe o reconhecimento das potenciais ofertas de apoio, refúgio e recursos a cada pessoa. Nessa direção, enquanto que a rede social se refere às características estruturais das relações sociais, por rede de apoio se entende o subconjunto dessas relações, ou seja, o reconhecimento e a valoração estratégica dos vínculos, que desempenham as diferentes funções do Apoio Social, apresentadas a seguir (Gracia, 1997; Gracia, Herrero, \& Musitu, 2002). A Rede de Apoio pode ser distinguida entre o Sistema Informal e o Sistema Formal. O Sistema Informal é composto por família, amigos, vizinhos e instituições da sociedade civil (ONGs, instituições religiosas, associações e clubes) que, de alguma forma, prestam Apoio Social. O Sistema Formal compreenderia as instituições e serviços públicos que prestam atendimento, cuidado e suporte para os indivíduos e a sociedade. Nesse grupo poderíamos conceituar os serviços de saúde (Estratégia de Saúde da Família - ESF, Centro de Atenção Psicossocial - CAPS, ambulatórios e hospitais), serviços de assistência social (CRAS, CREAS, abrigos e albergues), conselho tutelar, juizados, escolas, INSS, departamento de habitação, entre outros.

Não existe um consenso a respeito da definição de Apoio Social. Esse conceito é composto por várias dimensões, que envolvem ao mesmo tempo a estrutura da rede de relacionamentos sociais e a adequação de sua função (Pinto, Garcia, Bocchi, \& Carvalhaes, 2006; Rosa,

Estudos de Psicologia, 23(2), abril a junho de 2018, 145-156 
Benício, Alves, \& Lebrão, 2007). Segundo dois autores clássicos sobre o assunto, o Apoio Social é um construto no qual o sujeito usa informações que o levam a sentir-se valorizado, cuidado e integrante de uma rede social de comunicação, com obrigações mútuas (Cobb, 1976), possuindo o efeito de minimizar (amortecer) os efeitos de estressores em situações de crise (Buffering-Stress Effects) e também o efeito de proporcionar benefícios para cotidiano das pessoas (Main Effects) (Cohen \& Wills, 1985). De acordo com Gracia et al. (2002), o Apoio Social é um conjunto de disposições percebidas (subjetivas) ou recebidas (reais), pelo qual os recursos da estrutura social (redes sociais, redes de apoio e vínculos) atendem - em diferentes níveis - as necessidades cotidianas ou de crise. O Apoio Social é comumente dividido na dimensão estrutural e funcional (Gracia, 1997; Gracia et al., 2002; Moreira \& Sarriera, 2008). A dimensão estrutural se refere aos pontos estruturais que configuram o Apoio Social, como a Participação Social (grau de implicação e participação do sujeito na vida social), a Rede Social (vínculos familiares, de amigos e colegas de trabalho) e a Integração Comunitária (número de relações mantidas pelo sujeito em uma comunidade). Já a dimensão funcional refere-se à percepção do sujeito quando a disponibilidade e forma de apoio que lhe é oferecido, sendo dividido em três funções: Apoio Emocional, Apoio de Informações e Apoio Material.

Desta maneira, este estudo pretende contribuir na compreensão da articulação da Rede de Apoio e do Apoio Social dos usuários da Assistência Social, especificamente na Proteção Social Básica, através da percepção de trabalhadores do CRAS e de seus usuários. $O$ estudo do Apoio Social no contexto da Assistência Social possibilita compreender como as relações que os usuários mantêm impactam no enfrentamento e nos efeitos estressores de adversidades. Os resultados dessa pesquisa poderão auxiliar na atuação e na avaliação dos serviços e programas ofertados pelos CRAS. Esta pesquisa está vinculada a um projeto financiado pelo MDS, desenvolvido nos anos de 2014 e 2015.

\section{Metodologia}

\section{Delineamento}

O presente estudo caracteriza-se como uma pesquisa do tipo exploratória e estruturada a partir de uma abordagem qualitativa. A pesquisa qualitativa ocupa-se de verificar os valores, crenças e atitudes, com interpretações das realidades sociais (Minayo, 2010). Os estudos exploratórios são desenvolvidos com o objetivo de proporcionar visão geral, do tipo aproximativo, acerca de determinado fato (Gil, 2006).

\section{Participantes}

Foram entrevistados dois grupos: o de profissionais e o de usuários. O primeiro grupo foi composto por 27 profissionais da psicologia que atuam no PAIF nos CRAS da cidade de Porto Alegre (capital do estado do Rio Grande do Sul) no ano de 2014. Essa amostra foi obtida através de uma lista fornecida pela Fundação de Assistência Social e Cidadania de Porto Alegre (FASC) e compreendia a totalidade de psicólogos atuando em CRAS em Porto Alegre em 2014. Não participaram da pesquisa apenas dois dos 29 psicólogos atuantes em CRAS naquele momento. Estas profissionais alegaram a intensa agenda de trabalho como motivo para não participarem da pesquisa. Já o segundo grupo foi integrado por quatro usuários que, no momento da pesquisa, estavam sendo acompanhados pelo PAIF, durante os anos de 2013 e 2014. Os quatro usuários foram selecionados da mostra total de 201 usuários participantes da pesquisa, a partir dos escores obtidos no Questionário de Apoio Social (Gracia et al, 2002) e no Inventário de Percepção de Suporte Familiar - IPSF (Baptista, 2007). O Questionário de Apoio Social permite obter informações nas dimensões de Rede de Apoio, funções de Apoio Social, Participação e Integração Comunitária e Apoio Social de Sistemas Informais e Formais. Já o Inventário de Percepção de Suporte Familiar avalia a percepção das relações familiares em termos de afetividade, autonomia e adaptação entre os membros. A partir desses escores, os participantes foram agrupados em casos prototípicos (Gray, 2012), ou seja, foram selecionados os quatro usuários com as pontuações extremas: Apoio Social mais alto, Apoio Social mais baixo, Suporte Familiar mais alto, Suporte Familiar mais baixo, caracterizando assim os participantes que representariam mais prototipicamente os conceitos estruturantes de cada instrumento utilizado no campo do apoio.

As entrevistas foram realizadas individualmente, após a leitura, esclarecimentos e assinatura do Termo de Consentimento Livre e Esclarecido (TCLE). Em relação às considerações éticas, o presente trabalho teve a aprovação do Comitê de Ética da Pontifícia Universidade Católica do Rio Grande do Sul (PUCRS). Os participantes foram informados individualmente sobre os objetivos, justificativa da pesquisa, os benefícios possíveis e a garantia de resposta a dúvidas no transcorrer da pesquisa. Foram utilizados nomes fictícios para o sigilo dos participantes. 


\section{Instrumentos}

Como instrumento para a coleta de informações, foram utilizadas a entrevista semi-dirigida para os profissionais e a entrevista narrativa para os usuários (Flick, 2009). As entrevistas foram gravadas em áudio, transcritas e posteriormente analisadas. As entrevistas semi- dirigidas buscaram reconstruir os conteúdos da teoria subjetiva de cada profissional sobre o apoio social e sobre os usuários acompanhados pelo PAIF, que seria a reserva complexa de conhecimentos sobre o tópico em estudo (Flick, 2009).

Já as entrevistas narrativas tiveram o objetivo de explorar como os aspectos da história de vida dos participantes estão associados aos recursos de Apoio Social e à Rede de Apoio ao longo do ciclo vital de cada usuário chave. Segundo Jovchelovitch e Bauer (2002), as entrevistas narrativas possuem um caráter histórico, processual e aberto, em que o entrevistador busca influenciar, interferir e interromper o mínimo possível a narrativa do participante. Baseando-se nestes aportes teóricos, as entrevistas narrativas não possuíram tempo previamente estipulado para término (Flick, 2009; Jovchelovitch \& Bauer, 2002). A pergunta inicial que proporcionou o início da narrativa do participante foi: "Poderia contar sua história de vida e como chegou até o CRAS?".

\section{Análise dos Dados}

A análise das informações obtidas através das entrevistas realizadas foram compreendidas a partir da perspectiva da Análise Temática (Braun \& Clarke, 2006). Este método de análise é flexível e pode ser utilizado com diferentes posicionamentos epistemológicos, não tem requisitos de amostragem e adequa-se a diversos tipos de dados qualitativos. Como propõem Braun e Clarke (2006), três etapas constituem a aplicação desta técnica de análise: a pré-análise, a exploração do material, o tratamento dos resultados e interpretação. A pré-análise teve início com a realização de uma atividade conhecida como "leitura flutuante", que objetivou gerar impressões iniciais acerca do material a ser analisado. $\mathrm{Na}$ exploração do material, codificaram-se as informações contidas no material, ou seja, recortou-se o texto buscando classificar os referidos recortes nas categorias temáticas.

\section{Resultados}

Os dados coletados e analisados, tanto das entrevistas com os profissionais quanto das realizadas com os usuários, foram divididos em dois eixos maiores: Redes e vínculos e Apoio Social. O eixo Redes e vínculos compreende as categorias a) Rede familiar, b) Rede comunitária e Institucional e c) Técnicos sociais. Já o eixo Apoio Social foi dividido de acordo com suas funções, nas categorias a) Apoio Emocional, b) Apoio de Informações e c) Apoio Material. A figura A1 apresenta uma rede semântica do conteúdo das entrevistas, relacionando as percepções dos usuários e dos trabalhadores de acordo com as categorias de análise apresentadas.

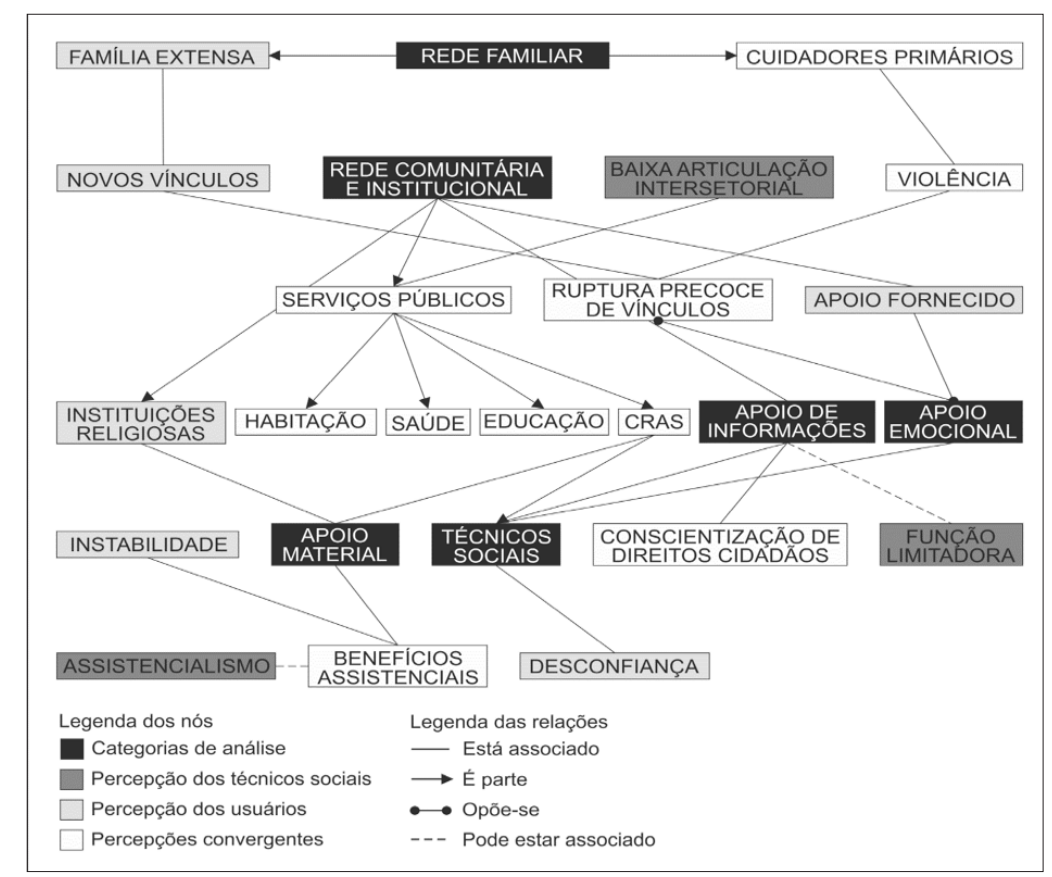

Figura 1. Rede Semântica do Conteúdo das Entrevistas. 


\section{Redes e Vínculos}

Neste eixo foram analisados aspectos referentes à rede familiar, à rede comunitária e institucional e ao vínculo com os profissionais (técnicos sociais). A rede familiar dos cuidadores primários encontra-se fragilizada. No entanto, há indícios de um fortalecimento da rede a partir do fortalecimento dos vínculos com os profissionais, da inserção dos usuários na rede de serviços públicos oferecidos na comunidade e de novos vínculos com a família extensa.

\section{Rede Familiar}

As narrativas dos usuários participantes acerca do tema rede familiar estão relacionadas a uma ruptura e/ou a um enfraquecimento precoce de vínculos com os cuidadores primários, precipitados por maus tratos ou negligência. Observa-se que a rede de apoio é reorganizada através de novos vínculos com a família extensa.

Eu fugi dos meus avós com 13 anos, 14 anos eu tive meu primeiro filho (...) que eu perdi [faleceu]. Então eu vim embora pra cá [Porto Alegre] porque o meu tio batia muito em mim. (...) Então [depois da fuga] eu vim morar na casa da minha cunhada aqui em Porto Alegre. (Rosa, 65 anos, casada, mora com o companheiro e a neta, 13 anos frequentando o serviço de Assistência Social. Caso prototípico: Apoio Social Alto)

Ela me conta que quando eu fiquei mal na casa dela [madrinha, cuidadora, mãe de criação], que deu meningite, eu fiquei mal e não era nem registrada (...) minha mãe não tinha nem me registrado. Daí minha madrinha me pegou, ficou com pena, já tava pegando amor em mim, né! Me pegou e me registrou, ela e meu padrinho, que não é meu padrinho, mas eu chamo de padrinho. (Joana, 41 anos, solteira, mora com um filho, dois meses frequentando o CRAS. Caso prototípico: Suporte Familiar Baixo)

A percepção de enfraquecimento da rede familiar também é compartilhada pelos profissionais e, por isso, ressaltam a importância de fortalecer os vínculos com a família. Os profissionais, porém, não mencionam a importância de novos vínculos para reconfiguração da rede de apoio, sobretudo com a família extensa, assim como foi encontrado nas narrativas dos usuários. "Quando ela [a família] entra pra acompanhamento, eu 'vejo ela' bem fragilizada, assim, e o trabalho que a gente faz também é de fortalecer, tanto dos serviços pra ela acessar, quanto pra suporte familiar." (Profissional)
É muito frágil, são redes [familiares] muito frágeis, eu vejo, que é claro que tem famílias que entre eles, eles se ajudam, mas a maioria não tem, a maioria é entre eles, não tem pai, não tem mãe, e se tem, é um por todos, não tem ninguém pra contar. (Profissional)

\section{Rede Comunitária e Institucional}

Para os usuários, as instituições religiosas estão fortemente relacionadas à rede comunitária, assim como os serviços públicos. Com relação a estes, incluem-se o CRAS, os serviços de saúde, habitação e educação. As instituições religiosas estão relacionadas ao apoio material. Os setores públicos podem ser considerados pontos importantes para a função de Apoio Social no contexto comunitário.

Terreiro é de Umbanda, sabe? Toda sexta-feira tem batuque, mas eu não frequento, mas eles me ajudam muito, eles me dão roupa, para as crianças, às vezes cesta básica, eles me mandam caixa de leite (...). Então 'Graças a Deus' daqui e dali sempre tem uma ajuda. (Maria, 57 anos, viúva, mora com dois filhos - um filho acamado com sofrimento mental - e um neto, há mais de 25 anos frequenta o serviço de Assistência Social. Caso prototípico: Suporte Familiar Alto)

Eu vim buscar a bombinha [asma] pra ele [cônjugue], agora a gente vai ser atendido pelo posto [ESF do território], a gente tá esperando [contratação do] o médico que vai atender ali mesmo e pegar o remédio ali mesmo pra a gente não ter que ir lá no Camaquã [UBS em que são atendidos]. A gente é bem atendido. (...) a gente recebeu essa casa do DEMHAB [Departamento Municipal de Habitação] (...) porque antes a gente morava lá na beira do Guaíba [rio], vocês lembram uns anos atrás quando teve enchente, na minha casa entrou água, 'era duas pecinhas', água escorria na parede. (Rosa)

Para os trabalhadores, a rede comunitária é percebida como uma estrutura, constituída por pessoas e instituições, que podem exercer uma função substituta da rede familiar, pois ela encontra-se muitas vezes enfraquecida. Também há uma percepção de que as instituições públicas fazem parte da rede comunitária de forma articulada. Contudo, a menor articulação intersetorial está relacionada com uma maior fragmentação das ações voltadas para o usuário, havendo uma menor eficácia dos serviços oferecidos. As instituições 
religiosas não foram mencionadas como forma de Apoio Social pelos trabalhadores.

Muitas vezes a rede é a assistência, e ainda é vista como a última esperança dessas famílias, que muitas vezes são bem desestruturadas. A maioria não tem uma rede de apoio, e a gente consegue exercer essa rede através das instituições que também podem atendê-los. (Profissional)

Nós reclamamos do Conselho Tutelar, o Conselho também reclama de nós. Reclamamos da saúde, a saúde reclama da escola, e assim por diante. É um jogo de empurra na ponta, né, e realmente eu não dou conta do meu trabalho, a saúde não dá conta, ninguém dá conta e não depende de nós. (Profissional)

\section{Vínculo entre Usuários e Técnicos Sociais}

Para os usuários, o vínculo com os técnicos sociais faz parte de sua rede de apoio, e é fonte importante de apoio emocional.

"É, [profissional] que é meu ombro, só ela que me ouve. Eu não tenho mais ninguém, eu não tenho parente, não tenho mãe, não tenho irmã, não tenho ninguém, só eu." (Maria)

Porém, em alguns momentos, o profissional pode ser visto com desconfiança pelo usuário, ou como intruso, dificultando a vinculação.

Expliquei minha situação pra ele [profissional], tive que rebolar [insistir] (...) mas não é bem assim pra te dar um rancho [Cesta Básica], (...) Eles vão te ouvir, eles pedem, eles te escutam, tu fala, fala, fala, tu repete, repete, repete (...) eles ficam assim ó: te analisando (...) Eles só dizem o seguinte: que é por ordens judiciais [que bloqueou o Bolsa Família], e que ordens judiciais é essa que eles não acham pelo computador? Isso aí pra mim é história [mentira, enrolação] (...) Eu não vou tá correndo atrás, me incomodando, isso aí é dinheiro do Estado, então eles pegam e fazem o que eles querem. (Robson)

Os profissionais referem-se à vinculação com o usuário como parte fundamental da atuação no CRAS e tem papel importante para a eficácia no trabalho na assistência social. A vinculação também é mencionada como função de apoio emocional. Dessa forma, os técnicos sociais inserem-se na rede de apoio dos usuários.

Acolher, isso é uma coisa que agente sabe fazer muito bem, né? A gente tem uma formação pra isso, tem uma escuta sensibilizada pra isso, e com essa escuta, com esse acolhimento, 'tu já iniciou' o vínculo. Então 'tu tem' a possibilidade de trabalho, porque sem o vinculo 'tu não tem'. (Profissional)

\section{Apoio Social}

O eixo Apoio Social foi divido entre Apoio Emocional, Apoio de informações e Apoio material, tangível e instrumental - conforme a dimensão funcional. Percebe-se que o CRAS e os técnicos sociais desempenham uma importante fonte de Apoio Social para os usuários.

\section{Apoio Emocional}

Os profissionais referiram-se ao apoio emocional como sendo uma necessidade que os usuários apresentam, muitas vezes, quando vêm buscar o apoio material e o apoio de informações. Eles compreendem que a situação em que o usuário busca auxílio é de grande vulnerabilidade e que o apoio emocional desempenha uma função de caráter protetivo e de amortecimento frente a situações estressoras.

Às vezes tu não precisa fazer nada, só precisa estar ali escutando e muitas vezes eu termino o atendimento e abraço. [usuário] '- Eu tô querendo BPC (Benefício da Prestação Continuada), mas aí o meu filho (...)', e aí tu vê que é uma angústia, e que ela precisava falar, e muitas vezes aquele abraço, aquela forma afetiva. Então eu vejo que as pessoas vêm assim frágeis, em questão de afeto. (Profissional)

Tu trabalhando uma coisa mais concreta as pessoas trazem com elas o sofrimento delas em função daquele filho não ter ido mais a escola, no meu grupo eu não consigo trabalhar 'ah hoje a gente vai falar sobre as condicionalidades, vamos então trabalhar só com a saúde, a questão das vacinas, vacina tal é pra isso é pra aquilo', eu não consigo trabalhar assim, tem sempre um viés mais emocional, mais profundo, algo que as pessoas deixam aqui. (Profissional)

Os usuários também identificam o apoio emocional fornecido pelos profissionais, como já foi demonstrado no item "Vínculos com os técnicos sociais". Com relação à rede comunitária, o apoio emocional relaciona-se com o apoio fornecido, através de ajudas prestadas e da troca de experiências.

Pra largar as mágoas às vezes eu converso com uma senhora, mas ela também tem problema. (...) Daí 
eu converso com ela, ela me conta a história dela, que também é crítica a condição dela, e eu conto a minha. Assim que a gente conversa. (Joana)

\section{Apoio de Informações}

O usuário entende esse tipo de apoio como uma possibilidade de conhecer e se beneficiar de recursos que eram desconhecidos.

"Fui vivendo, fui vivendo... daí, boatos de uns, boatos de outros, aí 'o meu!, tu não tá trabalhando, vai no CRAS ali... que eles 'faz' um benefício 'pras criança'". (Robson)

Entretanto, a relevância deste tipo de apoio é mais evidente e presente na fala dos profissionais, que referem como sendo uma das principais funções do CRAS, por promover a conscientização de direitos cidadãos.

Pra mim a função do CRAS (...) é de acolher esse usuário pra informá-lo, que acho que também o usuário da assistência, ele precisa muito, talvez o principal serviço é a questão da informação, como acessar determinados benefícios, determinados serviços, (...) a função do CRAS, se definiria como um serviço que tem que acolher, deve acolher os usuários, pra disseminar informação, pra ir fazendo essa articulação. (Profissional)

Contudo, esse papel de disseminação de informação também é gerador de frustração por parte de alguns técnicos sociais, que se sentem limitados e frustrados diante dessa função.

E isso me deu um grande choque, então essa expectativa de chegar aqui e fazer, atender, né? (...) e aí: 'eu vim só pegar a isenção do RG', então não tinha atendimento, não tem acompanhamento, então tu 'fica' um pouco frustrado assim nessa questão da expectativa, eu tinha uma surpresa do que podia ser o novo e o novo pra mim, meio que frustrou nessa questão né? de fazer só aquele atendimento focal, sabendo que eu poderia, que eu posso ainda, que eu a recém entrei, atender muito mais, mas que só vem buscar isso. (Profissional)

\section{Apoio Material}

Os usuários evidenciam a necessidade e a emergência de algum tipo de apoio material fornecido pela assistência social, que muitas vezes é o único auxílio em situações de vulnerabilidade social. Por essa razão, instabilidades no benefício podem causar ou intensificar essas situações de vulnerabilidade.
"O Bolsa Família me ajuda a pagar a água, a luz, o gás, que antes eu cozinhava na rua né, a [profissional] cansou de eu falar pra ela que eu fazia um buraco no chão e cozinhava ali" (Maria)

"Esse negócio do Bolsa-Família aí, umas quantas vezes pra mim já bloqueou. Bloqueou uma vez que minha mulher foi embora, levou o Bolsa-Família, na época era 30 pila [reais], na época fiquei com as crianças sozinho" (Robson)

Alguns profissionais entendem que, muitas vezes, benefícios socioeconômicos como cestas básicas, bolsa família, vales-transporte, entre outras, podem funcionar numa lógica paternalista e assistencialista. Para que isso não aconteça, os usuários devem ser bem instrumentalizados.

O caráter da cesta básica, ela é algo de agenciar. Bom, aconteceu algo com aquela família, uma determinada situação e aquela família naquele momento, ela tem esse caráter de agenciar, uma coisa de todo mês, aquela família vem buscar uma cesta básica, as cestas básicas chegam e elas ficam ali, e numa acolhida, numa visita domiciliar, tem um processo de avaliação, sempre deixando muito claro pro usuário que é naquele momento, pra não caírem nisso de 'Que bom então eu sei que todo mês eu tenho uma cesta básica garantida lá no serviço do CRAS'. (Profissional)

A gente trabalha no protagonismo das pessoas, não é protagonismo tu pegar e dar cestas, dar as passagens, de que forma tu vai conseguir trabalhar com essas pessoas esse protagonismo? Por que tu não 'consegue' dar outro tipo de respaldo, um curso, sei lá, uma outra coisa, um trabalho? Vamos apostar nessa pessoa, não tu 'pegar' e 'dar' tudo. (Profissional)

\section{Discussão}

No que diz respeito às redes e vínculos, trabalhadores e usuários mencionaram situações de violência, abandono, negligência e maus tratos no período da infância e adolescência e relacionadas aos cuidadores primários. Essas situações tornam-se objetos de intervenção do poder público pós-constituição de 1988, com a formulação de políticas sociais e com a construção de uma rede de proteção da infância e adolescência, da qual os participantes da pesquisa não tiveram acesso durante a infância, levando-se em consideração suas idades. Apesar disso, houve uma ampliação da rede de apoio informal como 
estratégia de enfrentamento às situações de vulnerabilidade vivenciadas. Observa-se o amparo principalmente por pessoas da família extensa (familiares consanguíneos) e também da comunidade (vizinhos, amigos ou conhecidos da família). Para melhor compreensão do cuidado proporcionado pela rede informal, resgatamos a ideia de circulação de crianças. Segundo Fonseca (2006), a circulação de crianças faz parte da estrutura, organização e rede de parentesco em grupos familiares, especialmente os que desenvolvem relações comunitárias mais estreitas, particularmente em momentos de crise (separação, morte, violência e abandono), instabilidade econômica e dificuldades de acesso aos serviços públicos, sendo uma prática relacionada a uma obrigação moral existente em diversos contextos comunitários, sendo descrito por Fonseca (2006) entre as classes mais pobres da sociedade, ainda que não exclusivamente. Compartilhar ou outorgar dimensões do cuidado de maneira informal com a família extensa ou comunidade é uma prática historicamente registrada em vários contextos e momentos, culminando, em última instância, em processos de adoção informal.

Ainda acerca da concepção de rede familiar, os profissionais ressaltaram a fragilidade dos vínculos e da rede, e não mencionaram as novas possibilidades de reconfiguração, como relatado pelos usuários. Existe a possibilidade que os trabalhadores centralizem seus esforços na manutenção dos vínculos com a família de origem, tal como preconizado na PNAS (MDS, 2004, 2009 , 2012) e nem ainda tenham restrições à formalização de outras configurações afetivas nos projetos personalizados de cuidado. No entanto, a mesma literatura propõe ampliar a concepção do grupo familiar para além do modelo nuclear, incorporando, assim, outras possibilidades de vínculos, preferencialmente na comunidade e no território de origem. O componente comunitário também é referido no Plano Nacional de Promoção, Proteção e Defesa do Direito de Crianças e Adolescentes à Convivência Familiar e Comunitária (Secretaria Especial dos Direitos Humanos, 2006), que destaca a importância do ambiente e vínculo comunitário a partir de instituições, serviços e programas sociais e das redes de Apoio Social que possibilitam a ampliação do cuidado para além das fronteiras das famílias nucleares ou da institucionalização do Estado.

As instituições religiosas foram percebidas pelos usuários como importante fonte de apoio material, através da doação de alimentos e roupas. No Brasil, historicamente as instituições religiosas buscam, a partir de modelos de caridade, auxiliar as pessoas mais necessitadas, sobretudo doentes e pobres (Yazbek, 2012). Segundo Valla e Coimbra Júnior (2005), muitas vezes pessoas com pouca renda buscam nas religiões conforto e alívio dos seus sofrimentos como estratégia para enfrentar a pobreza. Contudo, nos resultados da presente pesquisa, o apoio emocional relacionou-se mais frequentemente com o vínculo com os técnicos sociais do que com as instituições religiosas - que, por sua vez, relacionou-se mais fortemente com o apoio material. A PNAS contempla a participação da sociedade civil organizada (instituições religiosas, ONG's, associações etc.) na prestação de apoio material. Mas ao mesmo tempo em que supre as necessidades materiais imediatas, acaba, por vezes, trabalhando numa lógica de caridade e paternalista, desresponsabilizando o Estado e seu papel central na articulação da política de assistência social e na autonomia das famílias. Este paradoxo das políticas sociais é apontado por Yazbek (2012), no qual ocorre uma filantropização, uma despolitização e uma despublicização do social. De acordo com Habermas (2001), a emancipação é o elemento chave da autonomia, e diz respeito a pessoas e coletividades. Trata-se do equilíbrio crítico entre as questões relacionadas com a dominação/exploração social, com a objetividade social (reificada), a normatividade (ilegítima), a intersubjetividade (relações interesseiras, coercitivas) e a subjetividade (falsa consciência, autoengano). A emancipação passa por procedimentos capazes de alterar a rotina do cotidiano em nome da autonomia pessoal e de uma vida regulada por normas consensuais, de um relacionamento baseado no entendimento e no reconhecimento dos indivíduos como sujeitos, de uma práxis transformadora.

Os profissionais compreendem a importância da rede comunitária, mas no campo prático centram a atuação nos vínculos familiares e apresentam dificuldade de articular ações no contexto comunitário e com o sistema informal de apoio. Alguns estudos apontam que a prática de territorialização é pouco realizada pelos psicólogos (Oliveira, Dantas, Solon, \& Amorim, 2011; Oliveira et al., 2014). Os trabalhadores também referem problemas na articulação entre as instituições públicas. Os problemas relacionados à intersetorialidade referidos estão na desarticulação dos serviços públicos e na dificuldade de acesso da população, semelhante ao encontrado em alguns estudos (Borysow \& Furtado, 2013; Mioto \& Schütz, 2011).

Observou-se que os usuários incluem fortemente os trabalhadores na sua rede de apoio. A inclusão

Estudos de Psicologia, 23(2), abril a junho de 2018, 145-156 
destaca a relevância dos profissionais do CRAS na prestação de Apoio Social na vida dos usuários. Em algumas situações, porém, há desconfiança dos usuários em relação a certos trabalhadores dos CRAS. Essa desconfiança pode estar relacionada às ações de monitoramento do descumprimento das condicionalidades, que são compromissos que o usuário tem com o governo federal para receber benefícios socioassistenciais. As condicionalidades estão relacionadas à área da educação e da saúde, e em caso de descumprimento, os efeitos podem ser de advertência, bloqueio (um mês), suspensão (dois meses) e cancelamento (MDS, 2012). Por um lado, as condicionalidades em saúde e educação possibilitam inserir os usuários na rede de serviços, tornando-os sujeitos de direito. Por outro, os descumprimentos muitas vezes culpabiliza, responsabiliza e individualiza os sujeitos e as famílias por problemas sociais e macroestruturais.

Os profissionais ainda referem-se à necessidade de apoio emocional dos usuários quando chegam ao CRAS em busca de outras formas de apoio. Semelhante à vinculação, a prestação de apoio psicológico é corriqueiramente vinculada à prática terapêutica do profissional de psicologia, principalmente no campo da clínica. As Orientações Técnicas sobre o PAIF (MDS, 2012) atentam para que as ações do psicólogo não devam possuir caráter terapêutico, clínico ou psicoterápico. No entanto, o mesmo texto destaca a importância do trabalho com a subjetividade, ou seja, que o psicólogo utilize seus conhecimentos para atender e acompanhar as famílias através da escuta dos aspectos subjetivos, relacionado às situações de vulnerabilidade. A partir dessa escuta, possibilita-se abrir um espaço para o usuário compartilhar afetos, pensamentos, relações e intimidades, estabelecendo-se um vínculo emocional com o usuário.

Os usuários relacionam o Apoio Informacional como uma possibilidade de conhecer e se beneficiar de recursos que eram desconhecidos, proporcionado pelas pessoas da comunidade e pelos serviços públicos, no cotidiano ou em momentos de crise. Os trabalhadores entendem o apoio de informações como uma das principais funções do CRAS. O apoio de informações, provido através de orientações, ocorre nas práticas de acolhimento, encaminhamento, atendimento, oficina, grupo, visita domiciliar etc. No entanto, a função de prover apoio de informações provoca frustração em alguns profissionais, por estar relacionado a uma percepção de que essa atividade é impessoal e objetiva, diferenciando-se da idealização e formação acadêmica.
Acerca do apoio material, foi evidenciada pelos usuários a necessidade desse suporte pela política de assistência social, sendo que muitas vezes é o único auxílio em situações de vulnerabilidade. O principal apoio disponibilizado pelo CRAS são os programas de transferência de renda como o Programa Bolsa Família (PBF). Dentre os objetivos dos programas de transferência de renda está o alívio das necessidades materiais imediatas (MDS, 2004). Pela centralidade que os benefícios sociais possuem no apoio material e na vida dos usuários, qualquer instabilidade no recebimento pode agravar a situação de vulnerabilidade, conforme relatado pelos usuários. Quanto às falas dos profissionais, estes entendem que o apoio material, provido principalmente através dos benefícios socioassistenciais (cestas básicas, Programa Bolsa Família, Benefício da Prestação Continuada, vale-transporte, etc) pode potencializar uma lógica assistencialista. Convergindo a isso, outro discurso destacado nas entrevistas pelos profissionais remete à necessidade de instrumentalização, visando à autonomia dos usuários. Pereira e Guareschi (2014) relatam em seu estudo que muitos profissionais apontam para a responsabilização dos usuários por sua condição de pobreza e desconsideram os aspectos sociais, políticos e econômicos que estão na origem dessas situações. As concepções deficitárias acerca das problemáticas que têm origem nas dimensões sociais, políticas e econômicas parecem relacionadas às concepções individualizantes de sujeito. Isso possibilita pensar que as práticas profissionais que estão sendo executadas no campo da assistência podem desempenhar mais tutela e controle do que a autonomia e a emancipação-focos chave da proteção social básica (Benelli \& Costa-Rosa, 2012). Conforme afirma Teixeira (2010), o trabalho social ainda carece de aportes teóricos e metodológicos para um novo trato à pobreza que supere a psicologização dos problemas sociais, ou o seu contrário, as visões socialmente deterministas e sem soluções práticas para o cotidiano. As falas dos profissionais entrevistados ainda parecem confundir aspectos de responsabilização individualizante com análises de singularização de potencialidades e demandas das pessoas.

\section{Conclusões}

Os resultados identificaram uma rede familiar enfraquecida por relações de maus tratos e negligência na trajetória dos usuários acompanhados pelo PAIF, o que não deixa de justificar a sua existência enquanto 
política de atenção cidadã. A Política Nacional de Assistência Social (PNAS), através da Proteção Social Básica, ao assegurar que suas ações tenham centralidade no acompanhamento familiar e na proteção ao rompimento de vínculos comunitários, pretende prevenir situações de risco de vulnerabilidade social. Essas diretrizes convergem com as necessidades dos usuários encontradas pela pesquisa. Os técnicos sociais, psicólogos, compreendem que sua atuação deve dirigir-se a articular uma rede de apoio, no qual eles mesmos se incluem, caracterizando-se por ambos os grupos como fontes de apoio emocional, com potencial de fortalecimento do bem-estar e promotores de proteção a eventos e situações estressoras aos usuários. Contudo, identifica-se na pesquisa a noção da rede familiar precisa ser ampliada pelos profissionais, para que se possam visualizar as vastas possibilidades de vinculação que os usuários relatam em suas narrativas, como com membros da família extensa e com dispositivos como as instituições religiosas, que têm um papel importante na função de Apoio Social na comunidade.

Os serviços públicos, especialmente os CRAS, se destacaram na rede comunitária e institucional do usuário. A esse respeito, os técnicos sociais entendem que muitas vezes a rede encontra-se fragmentada, ou seja, não possui uma articulação intersetorial com o objetivo de prestar um serviço integrado ao usuário, o que torna as ações menos eficazes. $O$ apoio de informações é considerado como o principal tipo de Apoio Social fornecido pelo CRAS, promovendo a conscientização de direitos do cidadão. Contudo, essa função é vista como limitadora por alguns profissionais, que se frustram ao ter expectativas diferentes a respeito da atuação na assistência social. Já o apoio material, através de benefícios socioeconômicos, possui um caráter emergencial em situações de vulnerabilidade social. Para que esses recursos possam ser eficazes e beneficiar o usuário, devem promover sua autonomia. Por isso, os técnicos sociais ressaltam a necessidade de trabalhar com a instrumentalização e o protagonismo das famílias acompanhadas pelo PAIF. Mesmo sem almejar generalizações para além dos dados levantados no contexto e no momento da pesquisa, a análise aqui apresentada pode potencializar a ação de profissionais e gestores da área, posto apresentar elementos da percepção de usuários chave sobre os serviços e processos de trabalho no campo da proteção social básica. Da mesma forma, ao apresentarmos de forma integrada a análise das entrevistas dos psicólogos da área, fomenta-se a discussão sobre os processos de trabalho no campo do apoio social na proteção social básica e como algumas visões sobre as pessoas lá atendidas e comprometem ou potencializam ações diretas e intersetoriais.

\section{Referências}

Baptista, M. N. (2007). Inventário de Percepção de Suporte Familiar (IPSF): estudo componencial em duas configurações. Psicologia: Ciência e Profissão, 27(3), 496-509. doi: 10.1590/S1414-98932007000300010

Benelli, S., \& Costa-Rosa, A. (2012). Paradigmas diversos no campo da assistência social e seus estabelecimentos assistenciais típicos. Psicologia USP, 23(4), 609-660. doi: 10.1590/S0103-65642012000400002

Borysow, I. C., \& Furtado, J. P. (2013). Acesso e intersetorialidade: o acompanhamento de pessoas em situação de rua com transtorno mental grave. Physis: Revista de Saúde Coletiva, 23(1), 33-50. doi: 10.1590/S0103-73312013000100003

Braun, V., \& Clarke, V. (2006). Using thematic analysis in Psychology. Qualitative Research in Psychology, 3(2), 77-101. doi: 10.1191/1478088706qp063oa

Cobb, S. (1976). Social support as a moderator of life stress. Psychosomatic Medicine, 38(5), 300-314 doi: 10.1097/00006842-197609000-00003

Cohen, S., \& Wills, T. A. (1985). Stress, social support, and the buffering hypothesis. Psychological Bulletin, 98(2), 310-57. doi: 10.1037/0033-2909.98.2.310

Dabas, E. (1995). La intervención en red. In E. Dabas (Org.), Red de Redes: las prácticas de la intervención en redes sociales (pp. 15-32). Buenos Aires: Paidós.

Flick, U. (2009). Introdução à pesquisa qualitativa (3a ed.; J. E. Costa, Trad.). Porto Alegre: Artmed.

Fonseca, C. (2006). Da circulação de crianças à adoção internacional: questões de pertencimento e posse. Cadernos Pagu, 26, 11-43. doi: 10.1590/S0104-83332006000100002

Gil, A. C. (2006). Métodos e técnicas de pesquisa social. São Paulo: Atlas.

Gracia, E. (1997). El apoyo social en la intervención comunitaria. Barcelona: Paidós.

Gracia, E., Herrero, J., \& Musitu, G. (2002). Evaluación de recursos y estresores psicosociales en la comunidad. Madrid: Síntesis.

Gray, D. E. (2012). Pesquisa no mundo real. (2 $2^{\mathrm{a}} \mathrm{ed}$.). Porto Alegre: Penso.

Habermas, J. (2001). Teoría de la acción comunicativa: complementos y estudios prévios (4⿳亠丷a ed., M. J. Redondo, Trad.). Madrid: Cátedra. (Obra original publicada em 1984)

Hermel, J. S., Rocha, K. B., Uribe, M. C., \& Pizzinato, A. (2016). El autocuidado y apoyo social de mujeres de un proyecto de seguimiento mamográfico en Porto Alegre/Brasil. Psicooncología, 13(1), 39-58. doi: 0.5209/rev_PSIC.2016.v13.n1.52486

Jovchelovitch, S., \& Bauer, M. W. (2002). Entrevista narrativa. In M. W. Bauer \& G. Gaskell G. (Orgs.), Pesquisa qualitativa com texto, imagem e som: um manual prático (pp. 90-113). Petrópolis: Vozes.

Klefbek, J. (2000). Terapia de red: un método de tratamiento en situaciones de crisis. Sistemas Familiares, 16(1), 47-78. 
Lietz, C. A., Lacasse, J. R., \& Cacciatore, J. (2011). Social support in successful reunification: A qualitative study. Journal of Family Social Work, 14(1), 3-20. doi: 10.1080/10522158.2011.531454

Minayo, M. C. D. S. (2010). O desafio do conhecimento: pesquisa qualitativa em saúde. (12ª ed.). São Paulo: Hucitec-Abrasco.

Ministério do Desenvolvimento Social e Combate à Fome. (2004). Política Nacional de Assistência Social - PNAS/ 2004. Brasília, DF: Secretaria Nacional de Assistência Social.

Ministério do Desenvolvimento Social e Combate à Fome (2006). Norma Operacional Básica de Recursos Humanos no SUAS - NOB- RH/ SUAS. Brasília, DF: Secretaria Nacional de Assistência Social.

Ministério do Desenvolvimento Social e Combate à Fome (2009). Orientações técnicas Centro de Referência de Assistência Social CRAS. Brasília, DF: Ministério do Desenvolvimento Social e Combate à Fome.

Ministério do Desenvolvimento Social e Combate à Fome (2012). Orientações técnicas Sobre o PAIF - O Serviço de Proteção e Atendimento Integral à Família - PAIF, segundo a Tipificação Nacional de Serviços Socioassistenciais. Brasília, DF: Ministério do Desenvolvimento Social e Combate à Fome.

Mioto, R. C.T., \& Schütz, F. (2011). Intersetorialidade na Política Social: reflexões a partir do exercício profissional dos assistentes sociais. Pelotas-RS: DIPROSUL.

More, C. L. O. O. (2005). As redes pessoais significativas como instrumento de intervenção psicológica no contexto comunitário. Paidéia, 15(31), 287-297. doi: 10.1590/S0103-863X2005000200016

Moreira, M. C., \& Sarriera, J. C. (2008). Satisfação e composição da rede de Apoio Social a gestantes adolescentes. Psicologia em Estudo, 13(4), 781-789. doi: 10.1590/S1413-73722008000400016

Oliveira, I. F., \& Amorim, K. M. O. (2012). Psicologia e política social: o trato da pobreza como "sujeito psicológico". Psicologia Argumento, 30(70), 559-566. doi: 10.1590/S0102-37722010000500002

Oliveira, I. F., Dantas, C. M. B., Solon, A. F. A. C., \& Amorim, K. M. O. (2011). A prática psicológica na proteção social básica do SUAS. Psicologia \& Sociedade, 23(n. spe), 140-149. doi: 10.1590/S0102-71822011000400017

Oliveira, I. F., Oliveira, N. L. A., Nascimento, M. N. C., Araújo, R. L., Coelho-Lima, F., \& Oliveira, K. M. (2014). Atuação dos psicólogos nos CRAS do interior do RN. Revista Psicologia \& Sociedade, 26(n. spe 2), 103-112. doi: 10.1590/S0102-71822014000600011

Pereira, V. T., \& Guareschi, P. A. (2014). Representações sociais da psicologia sobre os usuários do CRAS: culpabilização dos sujeitos em situação de vulnerabilidade social. Diálogo, (26), 9-24. https:// revistas.unilasalle.edu.br/index.php/Dialogo/article/view/1626/1152

Pinto, J. L. G., Garcia, A. C. D. O., Bocchi, S. C. M., \& Carvalhaes, M. A. B. L. (2006). Características do Apoio Social oferecido a idosos de área rural assistida pelo PSF. Ciência \& Saúde Coletiva, 11(3), 753-764. doi: 10.1590/S1413-81232006000300023

Rosa, T. E. C., Benício, M. H. D., Alves, M. C. G. P., \& Lebrão, M. L. (2007). Aspectos estruturais e funcionais do Apoio Social de idosos do município de São Paulo, Brasil. Cadernos de Saúde Pública, 23(12), 2982-2992. doi: 10.1590/S0102-311X2007001200019

Secretaria Especial dos Direitos Humanos (2006). Plano Nacional de Promoção, Proteção e Defesa do Direito de Crianças e Adolescentes à Convivência Familiar e Comunitária. Brasília, DF: Autor.

Sluzki, C. E. (1997). A rede social na prática sistêmica: alternativas terapêuticas. São Paulo: Casa do Psicólogo.

Teixeira, S. M. (2010). Trabalho Interdisciplinar nos CRAS: um novo enfoque e trato à pobreza. Textos \& Contextos, 9(2), 286-297. Recuperado de http://revistaseletronicas.pucrs.br/ojs/index.php/ fass/article/viewArticle/7032

Valla, V. V., \& Coimbra Júnior, C. E. (2005). Classes populares, Apoio Social e emoção: propondo um debate sobre religião e saúde no Brasil. In M. C. S. Minayo \& C. E. A Coimbra Júnior (Orgs.), Críticas e atuantes: ciências sociais e humanas em saúde na América Latina (pp. 77-89). Rio de Janeiro: Fiocruz.

Yazbek, M. C. (2012). Pobreza no Brasil contemporâneo e formas de seu enfrentamento. Serviço Social \& Sociedade, 110, 288-322. doi: 10.1590/S0101-66282012000200005 
Rede de apoio e apoio social na proteção social básica

Adolfo Pizzinato, Doutor em Psicologia pela Universitat Autònoma de Barcelona (UAB), é Professor do Programa de Pós-Graduação em

Psicologia da Universidade Federal do Rio Grande do Sul (UFRGS).

Endereço para correspondência: Instituto de Psicologia, Rua

Ramiro Barcelos, 2600, sala 104, CEP - 90035003, Porto Alegre, RS.

Telefones: (51) 3308-5261 ou (51) 3308-5246. Fax: (51) 3308-5473.

E-mail: adolfopizzinato@hotmail.com

Esequiel Pagnussat, Mestre em Psicologia pela Pontifícia Universidade

Católica do Rio Grande do Sul (PUC-RS), é Professor do curso de

Psicologia da Universidade Potiguar (UNP) - Campus Mossoró, RN,

e Doutorando do PPG em Psicologia da Universidade Federal do Rio

Grande do Norte (UFRN). E-mail: esequiel.pagnussat@yahoo.com.br

Ezequiel Simonetti Cargnelutti, Graduando em Psicologia pela Pontifícia Universidade Católica do Rio Grande do Sul (PUC-RS). E-mail: ezequielcargnelutti@gmail.com

Nathália dos Santos Lobo, Graduanda em Psicologia pela Pontifícia Universidade Católica do Rio Grande do Sul (PUC-RS).

E-mail: nathalia.lobo@acad.pucrs.br

Roberta Fin Motta, Doutora em Psicologia pela Pontifícia Universidade Católica do Rio Grande do Sul (PUC-RS), é Professora do Curso de Graduação em Psicologia da (PUC-RS).

E-mail: robertafmotta@gmail.com

Recebido em 02.Ago.16

Revisado em 20.Ago.17

Aceito em 13.Ago.18 